\title{
Correlations of Vascular Architecture and Angiogenesis with Pituitary Adenoma Histotype
}

\author{
Shingo Takano, Hiroyoshi Akutsu, Takuma Hara, \\ Tetsuya Yamamoto, and Akira Matsumura \\ Department of Neurosurgery, Faculty of Medicine, University of Tsukuba, 1-1-1 Tennodai, Tsukuba, Ibaraki 305-8575, Japan \\ Correspondence should be addressed to Shingo Takano; shingo4@md.tsukuba.ac.jp
}

Received 17 July 2014; Accepted 16 October 2014; Published 9 November 2014

Academic Editor: Daizo Yoshida

Copyright (c) 2014 Shingo Takano et al. This is an open access article distributed under the Creative Commons Attribution License, which permits unrestricted use, distribution, and reproduction in any medium, provided the original work is properly cited.

\begin{abstract}
Vascular endothelial growth factor (VEGF) is a potent angiogenic factor in solid tumors. However, its role in angiogenesis in pituitary adenoma is controversial. Angiogenesis in solid tumors including pituitary adenoma is commonly evaluated by microvascular density (MVD). Here, we evaluated MVD and the role of VEGF in vascular architecture in 51 pituitary adenomas (24 nonfunctioning, 13 prolactin-secreting, 10 growth hormone-secreting, 3 adrenocorticotropic hormone-secreting, and 1 thyroidstimulating hormone-secreting). Paraffin sections were stained with CD34 and VEGF. MVD and vascular architecture parameters (vessel area, diameter, perimeter, and roundness) were evaluated in CD34-stained sections. Immunohistochemistry showed 27/51 tumors (53\%) were VEGF-positive. There were no significant differences in MVD, any vascular parameter, or adenoma volume between VEGF-positive and VEGF-negative tumors. VEGF mRNA expression was significantly higher in VEGF-positive tumors. There were no significant correlations between VEGF mRNA expression and MVD or vascular parameters. However, vessel diameter and perimeter were significantly larger in prolactin-secreting than nonfunctioning and growth hormone-secreting macroadenomas. The difference in vessel diameter was observed among both VEGF-positive and all adenomas (micro- and macroadenoma). Thus, VEGF may have limited roles in the development of vascular architecture and tumor angiogenesis in pituitary adenomas, but the differences in vessel architecture by histotype (i.e., larger vessel diameter and perimeter in prolactinsecreting adenomas) suggest the hormonal regulation of vessel architecture rather than angiogenesis
\end{abstract}

\section{Introduction}

Angiogenesis, a fundamental process in tumor growth and development, is less prominent in adenomas than normal pituitary tissue [1-3]. The behavior of angiogenesis as a function of hormonal secretion and other characteristics of pituitary tumors remain controversial [4-8]. Vascular endothelial growth factor (VEGF) is a potent angiogenic factor expressed in many solid tumors [9]. It is considered an important biomarker in pituitary neoplasms [10]. VEGF was discovered in the conditioned medium of pituitary follicular cells in 1989 [11] and is still focused there as of 2012 [12]. Moreover, VEGF may be an important humoral factor for both normal and tumorous pituitary tissues.

The degree of angiogenesis in solid tumors including pituitary adenomas is commonly evaluated by microvascular density (MVD), in which the number of vessels in a given area is counted. However, angiogenesis possesses many aspects of neovascularization, such as vessel number, branching pattern, diameter, and shape. Among pituitary hormones, prolactin (PRL) and adrenocorticotropic hormone (ACTH) are reported to be related to vascular development and endothelial cell function [13-15]. Therefore, these hormone-secreting adenomas may have different vasculature and angiogenic characteristics compared to other types of adenomas.

Therefore, this study determined the roles of VEGF in angiogenesis and vascular architecture in pituitary adenomas. In addition, the differences in vascular architecture parameters other than MVD were determined between different histotypes of pituitary adenomas.

\section{Materials and Methods}

2.1. Pituitary Adenoma Samples. A total of 51 pituitary adenomas (24 nonfunctioning, 13 PRL-secreting, 10 growth 


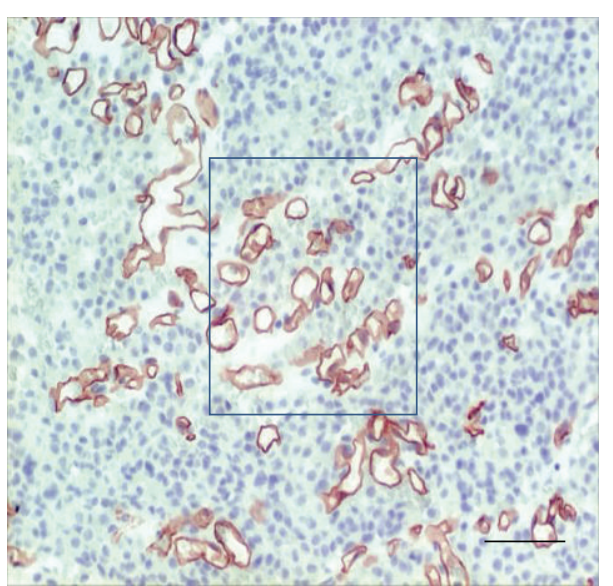

(a)

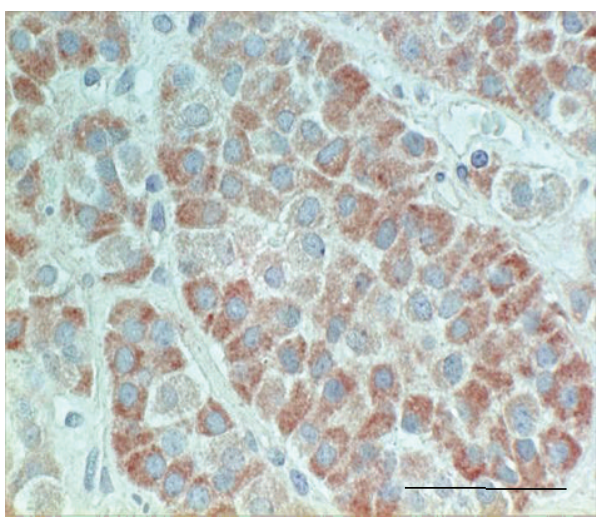

(c)

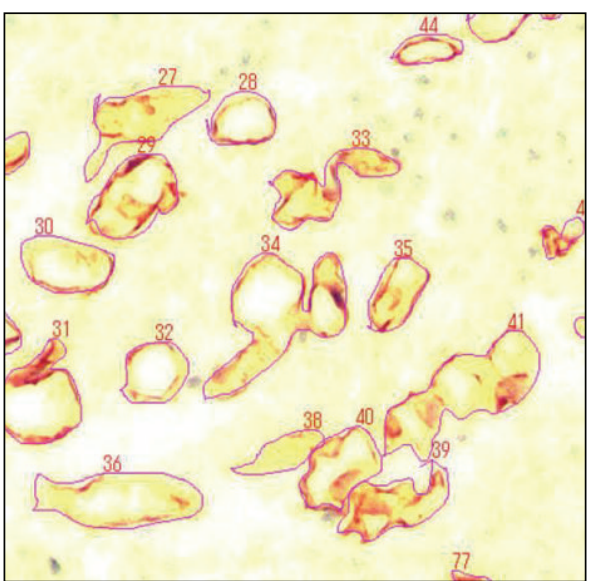

(b)

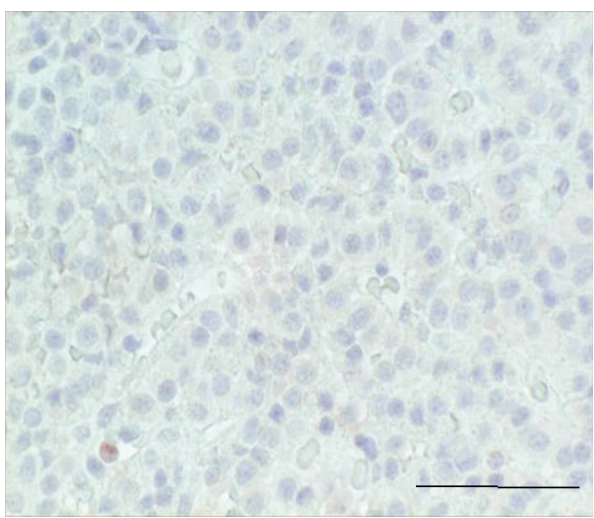

(d)

FIGURE 1: Determination of microvascular density and vascular architecture (a, b) and VEGF immunohistochemistry (c, d). CD34-stained fields $\left(1.0 \mathrm{~mm}^{2}\right.$ ) (a) are input into the image analyzer, and each vessel contour is manually traced in order to measure vessel density (number), vessel area (\%), vessel diameter $(\mu \mathrm{m})$, vessel perimeter $(\mu \mathrm{m})$, and vessel roundness $(0-1)(\mathrm{b})$. The area of the black box in (a) is magnified to (b). VEGF immunohistochemistry: positive tumor with clear cytoplasmic staining (c) and negative tumor (d). Original magnification (a): 200x, (c), (d): 400x. Bar $100 \mu \mathrm{m}$.

hormone- (GH-) secreting, 3 ACTH-secreting, and 1 thyroidstimulating hormone- (TSH-) secreting) obtained during surgery were fixed in formalin, embedded in paraffin, and sectioned at $5 \mu \mathrm{M}$. The adenoma volume was measured by magnetic resonance imaging according to the 3-dimensional diameter (AP: maximum diameter of the anterior-to-posterior direction in a sagittal section; LR: maximum diameter of the left-to-right direction in a coronal section; up and down: maximum diameter of the up-todown direction in a coronal or sagittal section). The cystic component of the adenoma was measured separately and not included in the calculation. Macroadenomas (i.e., $>10 \mathrm{~mm}$ in diameter in one dimension) were observed in 24 of 24 nonfunctioning, 10 of 13 PRL-secreting, 8 of $10 \mathrm{GH}$-secreting, 2 of 3 ACTH-secreting, and 0 of $1 \mathrm{TSH}$-secreting adenomas. For functioning adenomas, preoperative serum hormone levels (i.e., GH, PRL, and ACTH) were determined.

2.2. CD34 and VEGF Immunohistochemistry and Measurement of Vascular Architecture. Paraffin sections were stained with monoclonal anti-CD34 antibody (1:100, M7165; Dako) and polyclonal anti-VEGF antibody (1:100, A20; Santa Cruz) by the streptavidin-biotin-peroxidase method (Dako LSAB2 System) as described previously [16]. The same concentrations of chromatographically purified mouse IgG and rabbit IgG (Dako) were used as negative controls. CD34-stained sections were evaluated for MVD, and vascular architecture parameters including vessel area, diameter, perimeter, and roundness were analyzed by using an image analyzer system (WinROOF, Mitani Corporation, Japan); WinROOF is an integrated software system for image processing, measurement, and data processing to support all image analysisrelated operations $[17,18]$. The defined area for the measurement of these parameters was $1.0 \mathrm{~mm}^{2}$. CD34-stained fields of $1.0 \mathrm{~mm}^{2}$ (Figure 1(a)) were input into the image analyzer, and each vessel contour was manually traced in order to measure vessel density (number), vessel area (\%), vessel diameter $(\mu \mathrm{m})$, vessel perimeter $(\mu \mathrm{m})$, and vessel roundness $(0-1$; $1=$ completely round) (Figure $1(\mathrm{~b})$ ). Three different fields in each case were measured, and the median values were used for analysis. VEGF immunohistochemistry was defined as positive if more than $10 \%$ of adenoma cells were positive. 
2.3. VEGF mRNA Expression by RT-PCR. Among the 51 pituitary adenomas, frozen tissues of 19 adenomas (12 nonfunctioning, 4 PRL-secreting, $2 \mathrm{GH}$-secreting, and 1 ACTH-secreting) were available. Total RNA was extracted, and VEGF mRNA expression was measured by RT-PCR as described previously [19]. Briefly, $1 \mu \mathrm{g}$ total RNA was reverse-transcribed by MuLV reverse transcriptase in the presence of random hexamers followed by the indicated cycles of PCR $\left(95^{\circ} \mathrm{C}\right.$ for $1 \mathrm{~min}, 55^{\circ} \mathrm{C}$ for $1 \mathrm{~min}$, and $72^{\circ} \mathrm{C}$ for $1 \mathrm{~min}$ ) in the presence of $2 \mu \mathrm{M}$ VEGF-specific primers (28 cycles) or $\beta$-actin-specific primers (16 cycles) as a control. The VEGF primers included the reverse primer $\left(5^{\prime}\right.$-CCTGGTGAGAGATCTGGTTC- $3^{\prime}$ ) spanning bases $861-842$ and the forward primer $\left(5^{\prime}\right.$-TCGGGCCTCCGAAACCATGA$\left.3^{\prime}\right)$ spanning bases $141-160$. The $\beta$-actin primers included the reverse primer $\left(5^{\prime}\right.$-GGAGTTGAAGGTAGTTTCGTG$\left.3^{\prime}\right)$ spanning bases $2429-2409$ and the forward primer $\left(5^{\prime}\right.$ CGGGAAATCGTGCGTGACAT- $3^{\prime}$ ) spanning bases 2107 2126. The VEGF primers were chosen because they amplified exons 3-8, enabling us to distinguish VEGF splicing variants. PCR products of 516 and 648 bp corresponded with $V_{E G F}{ }_{121}$ and VEGF 165 , respectively. RT-PCR products were quantified by densitometry.

2.4. Statistical Analysis. Vascular density, tumor volume, the densitometric values of VEGF and $\beta$-actin, and adenoma architecture parameters (i.e., area, diameter, perimeter, and roundness) are expressed as mean $\pm \mathrm{SD}$. The one-way ANOVA with post hoc Tukey's comparisons was used for multiple groups, while the $t$-test was used for comparisons of 2 groups. Pearson's correlation coefficients $(r)$ were also calculated. All $P$ values are two-sided, and the level of significance was set at $P<0.05$.

\section{Results}

3.1. VEGF Expression and Pituitary Adenoma. Immunohistochemistry showed 27/51 tumors (53\%) were positive for VEGF (Figures 1(c) and 1(d)). There were no significant differences between the VEGF-positive and VEGF-negative groups with respect to MVD, any vascular architecture parameter, or adenoma volume (Table 1). In 19 tumors, VEGF mRNA and protein expressions were measured simultaneously (Figure 2(a)). The $\mathrm{VEGF}_{165}$ /actin ratio was significantly higher in VEGF-positive tumors $(0.81 \pm 0.91)$ than negative tumors $(0.46 \pm 0.23)(P=0.045$, Figure $2(\mathrm{~b}))$. Likewise, the VEGF $_{121}$ /actin ratio was significantly higher in VEGFpositive tumors $(0.74 \pm 0.37)$ than negative tumors $(0.39 \pm$ $0.24)(P=0.019$, Figure $2(\mathrm{c}))$. There was no significant correlation between $\mathrm{VEGF}_{165}$ or $\mathrm{VEGF}_{121}$ mRNA expression and MVD or any vascular architecture parameter (Table 2, Figures 2(d), 2(e), 2(f), and 2(g)). Thus, these results indicate VEGF has only small roles in the vascular architecture and angiogenesis of pituitary adenomas.

3.2. Vascular Architecture in Different Histotypes of Pituitary Adenomas. The vascular architecture parameters in different histotypes of adenomas are shown in Table 3 and
TABLE 1

\begin{tabular}{|c|c|c|c|c|c|}
\hline & $\begin{array}{c}\text { VEGF } \\
\text { pos } \\
\text { mean } \\
\end{array}$ & SD & $\begin{array}{c}\text { VEGF- } \\
\text { negative } \\
\text { mean }\end{array}$ & $\mathrm{SD}$ & Statistics \\
\hline All cases & $n 27$ & & $n 24$ & & \\
\hline Density $/ 1.0 \mathrm{~mm}^{2}$ & 57.2 & 30.6 & 46.0 & 27.80 & ns \\
\hline Area \% & 7.17 & 5.54 & 5.24 & 2.89 & ns \\
\hline Diameter $\mu \mathrm{m}$ & 12.3 & 0.6 & 12.5 & 0.56 & ns \\
\hline Perimeter $\mu \mathrm{m}$ & 58.9 & 18.4 & 59.4 & 13.40 & ns \\
\hline Roundness & 0.55 & 0.06 & 0.55 & 0.08 & ns \\
\hline $\begin{array}{l}\text { Tumor volume } \\
\mathrm{mm}^{3}\end{array}$ & 28035.7 & 97661.7 & 4342 & 4500.9 & ns \\
\hline NF & $n 11$ & & $n 13$ & & \\
\hline Density $/ 1.0 \mathrm{~mm}^{2}$ & 63.8 & 11.1 & 50.6 & 8.50 & ns \\
\hline Area $\%$ & 7.13 & 5.37 & 5.49 & 3.00 & ns \\
\hline Diameter $\mu \mathrm{m}$ & 11.9 & 2.65 & 12.2 & 2.30 & ns \\
\hline Perimeter $\mu \mathrm{m}$ & 56.4 & 17.4 & 55.1 & 11.40 & ns \\
\hline Roundness & 0.56 & 0.03 & 0.58 & 0.08 & ns \\
\hline $\begin{array}{l}\text { Tumor volume } \\
\mathrm{mm}^{3}\end{array}$ & 13519.1 & 16887.9 & 6648.1 & 4654.6 & ns \\
\hline PRL & $n 7$ & & $n 6$ & & \\
\hline Density $/ 1.0 \mathrm{~mm}^{2}$ & 50.3 & 9.8 & 42.6 & 11.10 & ns \\
\hline Area \% & 9.19 & 5.18 & 5.73 & 3.12 & ns \\
\hline Diameter $\mu \mathrm{m}$ & 14.9 & 2.98 & 13.3 & 3.10 & ns \\
\hline Perimeter $\mu \mathrm{m}$ & 72 & 15.7 & 62.1 & 15.20 & ns \\
\hline Roundness & 0.515 & 0.054 & 0.545 & 0.05 & ns \\
\hline $\begin{array}{l}\text { Tumor volume } \\
\mathrm{mm}^{3}\end{array}$ & 8245.8 & 189920.0 & 2817.9 & 4305.9 & ns \\
\hline $\mathrm{GH}$ & $n 8$ & & $n 2$ & & \\
\hline Density $/ 1.0 \mathrm{~mm}^{2}$ & 51 & 27.1 & 59.4 & 15.10 & ns \\
\hline Area \% & 5.59 & 6.56 & 5.98 & 3.43 & ns \\
\hline Diameter $\mu \mathrm{m}$ & 10.8 & 2.8 & 10.8 & 2.10 & ns \\
\hline Perimeter $\mu \mathrm{m}$ & 52.1 & 18.9 & 56.8 & 12.50 & ns \\
\hline Roundness & 0.557 & 0.070 & 0.473 & 0.033 & ns \\
\hline $\begin{array}{l}\text { Tumor volume } \\
\mathrm{mm}^{3}\end{array}$ & 3842.1 & 5570.5 & 500.0 & 282.8 & ns \\
\hline ACTH & $n 0$ & & $n 3$ & & \\
\hline Density $/ 1.0 \mathrm{~mm}^{2}$ & nd & & 24.2 & 13.30 & nd \\
\hline Area $\%$ & nd & & 2.72 & 0.76 & nd \\
\hline Diameter $\mu \mathrm{m}$ & nd & & 13.5 & 4.70 & nd \\
\hline Perimeter $\mu \mathrm{m}$ & nd & & 66.5 & 20.70 & nd \\
\hline Roundness & nd & & 0.481 & 0.057 & nd \\
\hline $\begin{array}{l}\text { Tumor volume } \\
\mathrm{mm}^{3}\end{array}$ & nd & & 2264.8 & 1976.50 & nd \\
\hline TSH & $n 1$ & & $n 0$ & & \\
\hline Density $/ 1.0 \mathrm{~mm}^{2}$ & 51 & 27.1 & nd & & nd \\
\hline Area \% & 5.59 & 6.56 & nd & & nd \\
\hline Diameter $\mu \mathrm{m}$ & 10.8 & 2.8 & nd & & nd \\
\hline Perimeter $\mu \mathrm{m}$ & 52.1 & 18.9 & nd & & nd \\
\hline Roundness & 0.557 & 0.070 & nd & & nd \\
\hline $\begin{array}{l}\text { Tumor volume } \\
\mathrm{mm}^{3}\end{array}$ & 346.5 & nd & nd & & nd \\
\hline
\end{tabular}

Figure 3. Vessel diameter was significantly larger in PRLsecreting adenomas than $\mathrm{GH}$-secreting adenomas (Figure 4). Meanwhile, vessel density and area tended to be lower in 
U87 NF NF NF NF NF NF NF NF GH PRL NF NF NF NF GH PRL PRL PRL ACTH

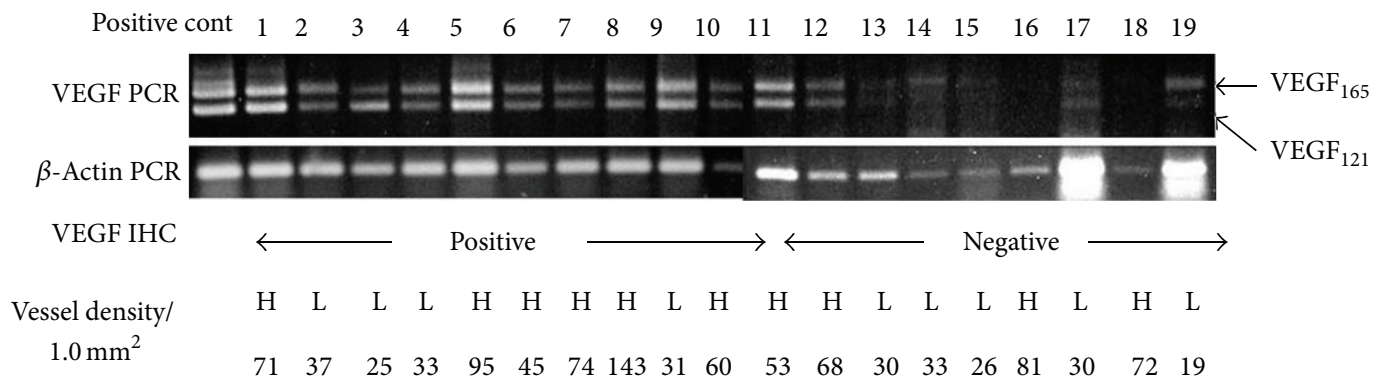

(a)

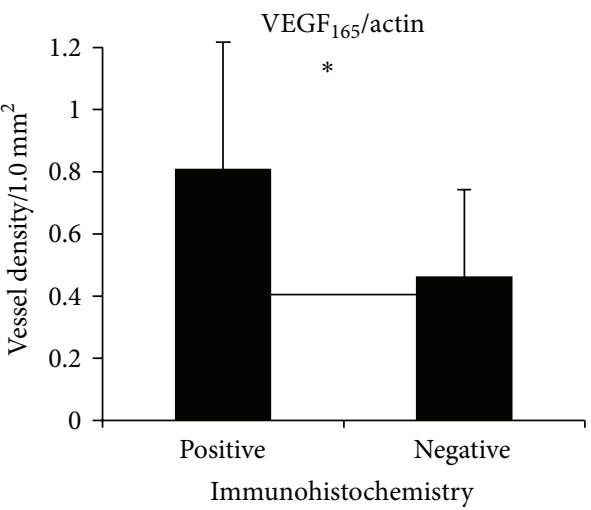

(b)

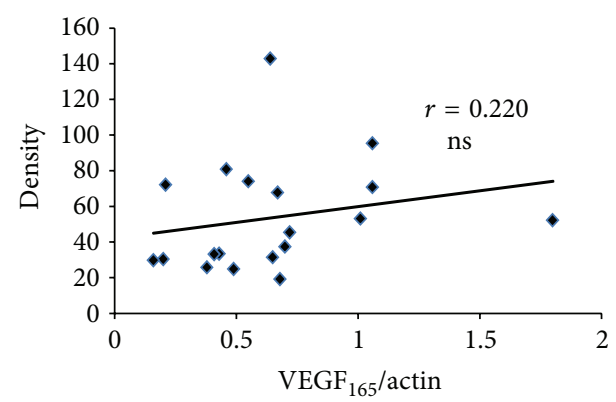

(d)

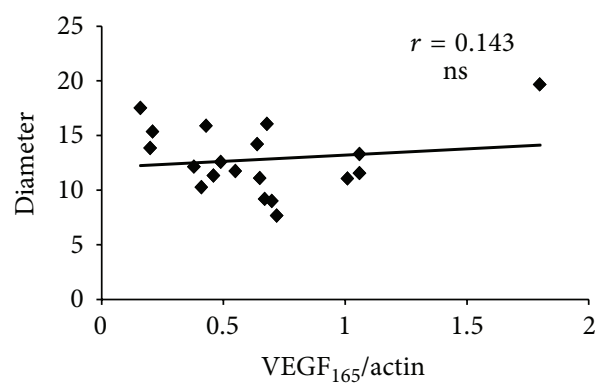

(f)

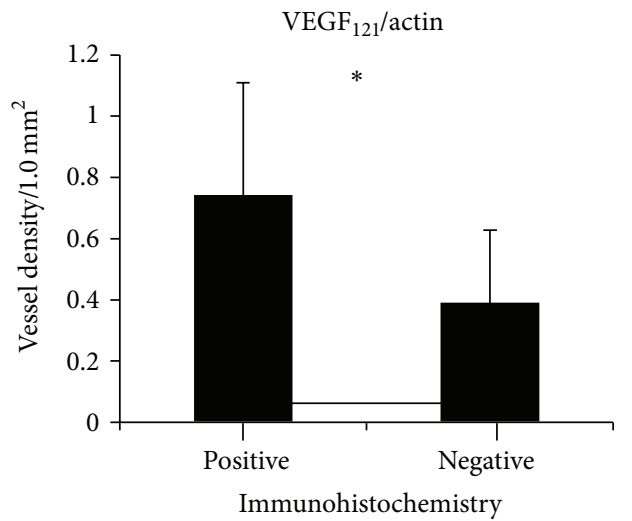

(c)

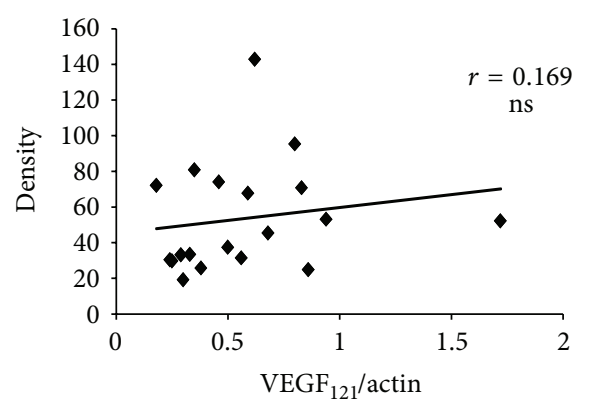

(e)

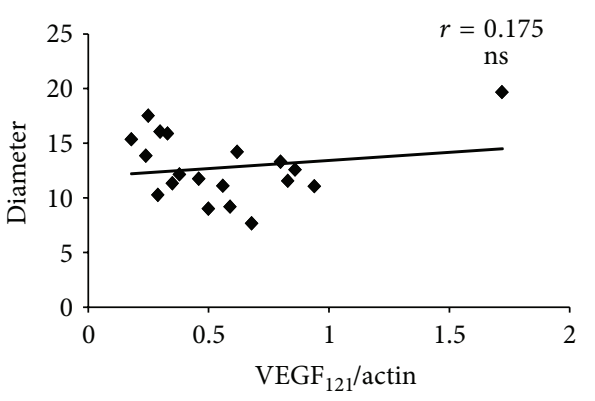

(g)

FIGURE 2: Determination of VEGF mRNA expression and immunohistochemistry. (a) VEGF mRNA expression and corresponding VEGF immunohistochemistry results (positive and negative) and vessel density (number/0.13 $\mathrm{mm}^{2}, H \geq 40, L<40$ ). (b) The VEGF $165 / \beta$-actin ratio was significantly higher in VEGF-positive group than the VEGF-negative group $(P<0.05)$. (c) The $\mathrm{VEGF}_{121} / \beta$-actin ratio was significantly higher in the VEGF-positive group than the VEGF-negative group $(P<0.05)$. (d) The correlation between VEGF $165 / \beta$-actin ratio and vessel density was not significant $(r=0.22)$. (e) Correlation between $\mathrm{VEGF}_{121} / \beta$-actin ratio and vessel density is not significant $(r=0.169)$. (f) Correlation between $\mathrm{VEGF}_{165} / \beta$-actin ratio and vessel diameter is not significant $(r=0.143)$. $(\mathrm{g})$ Correlation between $\mathrm{VEGF}_{121} / \beta$-actin ratio and vessel density is not significant $(r=0.175)$. 


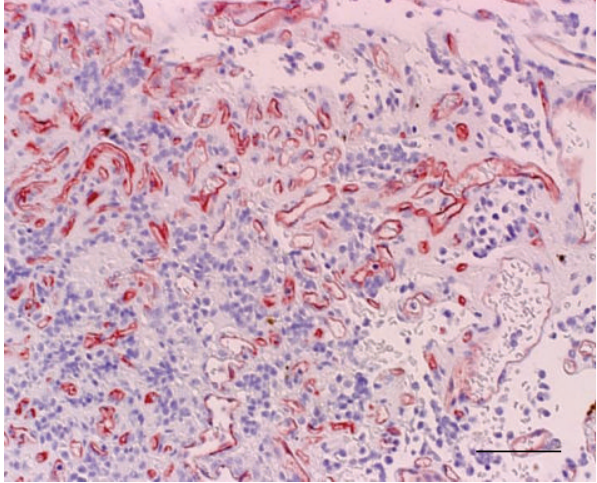

(a)

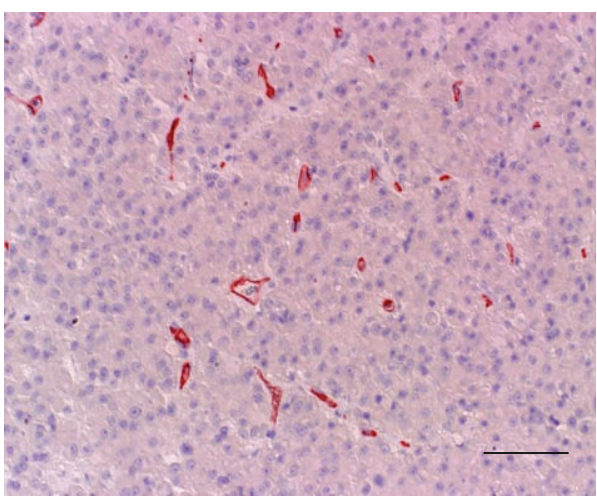

(c)

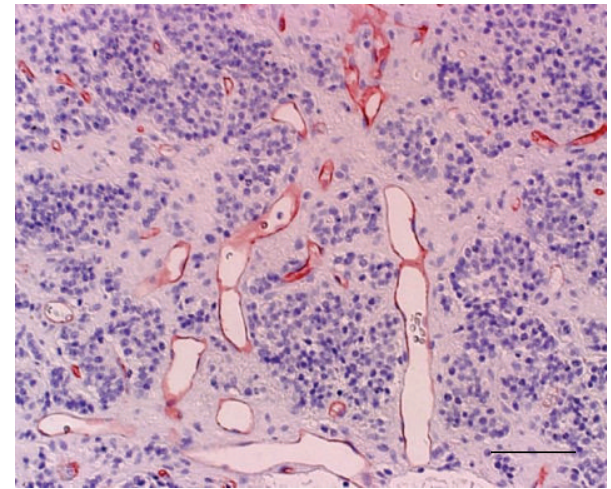

(b)

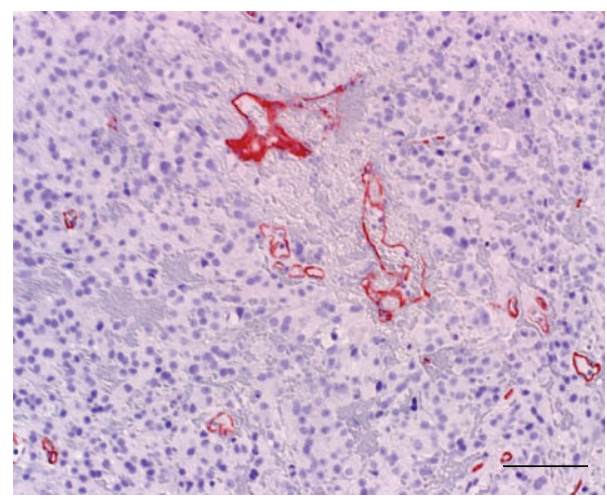

(d)

FIGURE 3: Representative vascular architecture (CD34 stain) of nonfunctioning (a), prolactin-secreting (b), GH-secreting (c), and ACTHsecreting (d) macroadenomas. Vessel diameter is larger in prolactin- and ACTH-secreting adenomas than nonfunctioning and GH-secreting adenomas. Vessel density and area are lower in ACTH-secreting adenoma than nonfunctioning and PRL-secreting adenomas. Original magnification: 200x. Bar $100 \mu \mathrm{m}$.

TABLE 2

\begin{tabular}{lccc}
\hline mRNA expression & Parameters & $r$ & Statistics \\
\hline \multirow{4}{*}{ VEGF165/actin } & Density & 0.220 & $\mathrm{~ns}$ \\
& Area & 0.301 & $\mathrm{~ns}$ \\
& Diameter & 0.143 & $\mathrm{~ns}$ \\
& Perimeter & 0.260 & $\mathrm{~ns}$ \\
& Roundness & -0.026 & $\mathrm{~ns}$ \\
& Tumor volume & 0.110 & $\mathrm{~ns}$ \\
\hline \multirow{4}{*}{ VEGF121/actin } & Density & 0.169 & $\mathrm{~ns}$ \\
& Area & 0.292 & $\mathrm{~ns}$ \\
& Diameter & 0.175 & $\mathrm{~ns}$ \\
& Perimeter & 0.218 & $\mathrm{~ns}$ \\
& Roundness & 0.056 & $\mathrm{~ns}$ \\
& Tumor volume & 0.270 & $\mathrm{~ns}$ \\
\hline
\end{tabular}

ACTH-secreting adenomas than nonfunctioning adenomas, although the differences were not significant. Because VEGF may influence vascular architecture, VEGF-positive adenomas alone $(n=27)$ were analyzed. Again, vessel diameter was significantly larger in PRL-secreting adenomas than GHsecreting adenomas. Because adenoma volume may influence vascular architecture, macroadenomas alone $(n=44)$ were analyzed. PRL-secreting adenomas had significantly larger perimeter and vessel diameter than nonfunctioning and GH-secreting adenomas (Figure 5). In summary, PRLsecreting adenomas, especially macroadenomas, have larger diameters and perimeters than nonfunctioning and $\mathrm{GH}$ secreting adenomas.

In PRL-secreting adenomas, serum PRL level was strongly correlated with adenoma volume $(r=0.9679$, $P<0.001$, Figure 6(a)). However, adenoma volume was not correlated with other vessel architecture parameters (density: $r=0.2008, P=0.5313$; area: $r=0.3315, P=0.2925$; diameter: $r=0.162, P=0.6146$; perimeter: $r=0.138, P=$ 0.6685 ; roundness: $r=-0.168, P=0.6014)$. Furthermore, in $\mathrm{GH}$-secreting adenomas, serum GH level was strongly correlated with adenoma volume $(r=0.9412, P<0.001$, Figure 6(b)).

\section{Discussion}

Vascular architecture parameters differed among adenoma histotypes. In macroadenomas, PRL-secreting adenomas had larger vessel diameter and perimeter than nonfunctioning and GH-secreting adenomas. In all adenomas (including 
TABLE 3: Morphometric analysis of vascular architecture between adenoma function.

\begin{tabular}{|c|c|c|c|c|c|c|c|c|c|c|}
\hline & $\begin{array}{c}\text { NF } \\
\text { mean }\end{array}$ & SD & $\begin{array}{c}\text { PRL } \\
\text { mean }\end{array}$ & $\mathrm{SD}$ & $\begin{array}{c}\mathrm{GH} \\
\text { mean }\end{array}$ & $\mathrm{SD}$ & $\begin{array}{c}\text { ACTH } \\
\text { mean }\end{array}$ & $\mathrm{SD}$ & $\begin{array}{c}\text { TSH } \\
\text { mean }\end{array}$ & \\
\hline All cases & $n 24$ & & $n 13$ & & $n 10$ & & $n 3$ & & $n 1$ & \\
\hline Density $/ 1.0 \mathrm{~mm}^{2}$ & 56.6 & 33.5 & 46.8 & 25.7 & 52.7 & 24.6 & 24.2 & 13.3 & 83 & \\
\hline Area \% & 6.24 & 4.24 & 7.59 & 4.55 & 5.66 & 5.90 & 2.72 & 0.76 & 6.27 & \\
\hline Diameter $\mu \mathrm{m}$ & 12.1 & 2.4 & $14.1^{*}$ & 3.0 & 10.8 & 2.6 & 13.5 & 4.7 & 9.58 & ${ }^{*} P<0.05$ to $\mathrm{GH}$ \\
\hline Perimeter $\mu \mathrm{m}$ & 55.7 & 14.2 & 67.5 & 15.7 & 53.0 & 17.3 & 66.5 & 20.7 & 47.5 & \\
\hline Roundness & 0.57 & 0.06 & 0.529 & 0.053 & 0.54 & 0.072 & 0.481 & 0.057 & 0.471 & \\
\hline VEGF-positive case & $n 11$ & & $n 7$ & & $n 8$ & & $n 0$ & & $n 1$ & \\
\hline Density $/ 1.0 \mathrm{~mm}^{2}$ & 63.8 & 36.7 & 50.3 & 25.9 & 51.0 & 27.1 & nd & & 83 & \\
\hline Area $\%$ & 7.13 & 5.37 & 9.19 & 5.18 & 5.59 & 6.56 & nd & & 6.27 & \\
\hline Diameter $\mu \mathrm{m}$ & 11.9 & 2.7 & $14.9^{*}$ & 3.0 & 10.8 & 2.8 & nd & & 9.58 & ${ }^{*} P<0.05$ to $\mathrm{GH}$ \\
\hline Perimeter $\mu \mathrm{m}$ & 56.4 & 17.4 & 72.0 & 15.7 & 52.1 & 18.9 & nd & & 47.5 & \\
\hline Roundness & 0.564 & 0.032 & 0.515 & 0.0543 & 0.557 & 0.0699 & nd & & 0.471 & \\
\hline Macroadenoma case & $n 24$ & & $n 10$ & & $n 8$ & & $n 2$ & & $n 0$ & \\
\hline Density $/ 1.0 \mathrm{~mm}^{2}$ & 56.6 & 33.3 & 44.3 & 24.1 & 49.2 & 24.9 & 16.7 & 23.3 & nd & \\
\hline Area \% & 6.2 & 4.2 & 8.4 & 4.6 & 5.7 & 6.60 & 3.1 & 0.32 & nd & \\
\hline Diameter $\mu \mathrm{m}$ & 12.1 & 2.4 & $15.2^{* *}$ & 2.4 & 11.1 & 2.8 & 16.2 & 0.2 & nd & ${ }^{* *} P<0.01$ to $\mathrm{NF}, \mathrm{GH}$ \\
\hline Perimeter $\mu \mathrm{m}$ & 55.7 & 14.2 & $72.7^{*}$ & 12.9 & 53.3 & 19.4 & 78.3 & 4.7 & nd & ${ }^{*} P<0.05$ to NF, GH \\
\hline Roundness & 0.571 & 0.064 & 0.527 & 0.060 & 0.558 & 0.069 & 0.503 & 0.060 & nd & \\
\hline
\end{tabular}

macro- and microadenomas) and VEGF-positive adenomas, vessel diameter in PRL-secreting adenomas was larger than that in GH-secreting adenomas. In addition, VEGF expression did not reveal any differences in MVD, vascular architecture, or tumor volume among adenoma histotypes. Thus, VEGF expression in pituitary adenoma has little effect on angiogenesis, vascular architecture, or histotype.

4.1. Role of VEGF in Pituitary Adenomas. VEGF is a potent angiogenic factor for solid tumors. The global standard for the measurement of tumor and physiological angiogenesis is immunohistochemical counting of vessels per defined hotspot area, that is, MVD, owing to its simplicity [20]. Therefore, angiogenesis of pituitary adenomas has been reported in many recent studies evaluating VEGF protein expression (measured by immunohistochemistry and western blot analysis), VEGF mRNA expression, and MVD. Nevertheless, the role of VEGF in angiogenesis in pituitary adenoma remains inconclusive. VEGF is reported to be a potent angiogenic factor in pituitary adenomas [4]. On the contrary, VEGF is found equally in normal tissue and adenomas and among tumors of different histotype [3]. Pituitary tumor cells are capable of producing VEGF, which may be involved in tumor angiogenesis [21]. Furthermore, VEGF mRNA and protein are expressed in all pituitary adenomas [22]. Thus, these findings suggest VEGF may not be a potent angiogenic factor in pituitary adenomas.

One of the reasons for these controversial results is the limitation of immunohistochemistry, which is semiquantitative. Also, MVD is only one aspect of neovascularization. Therefore, as an alternative, the present study evaluated angiogenesis by immunohistochemistry as well as mRNA expression to evaluate VEGF expression and vascular architecture parameters, and MVD.

A recent study demonstrates that VEGF mRNA expression differs among histological subtypes. The extension on magnetic resonance imaging indicates VEGF expression is related to suprasellar extension, being expressed more on tumors with extrasellar growth than intrasellar growth [23]. However, no relationship between VEGF expression and MVD was found in the present study. Hence, VEGF may be related to tumor growth (e.g., inhibition of apoptosis) but not tumor angiogenesis.

In the present study, high VEGF protein and mRNA expression did not reflect MVD, vascular architecture, tumor volume, or any particular histotype, suggesting VEGF plays little role in pituitary adenoma angiogenesis and growth. Stromal cell-derived factor-1 (SDF-1) is reported to be related to MVD in pituitary adenoma as a CD34-positive endothelial progenitor cell homing factor [24]. Hence, studies investigating the regulation of this novel angiogenic factor and VEGF in the angiogenesis of pituitary adenomas are warranted.

4.2. Vascular Architecture. MVD is one of the most widely used estimators of tumor microvascularity in twodimensional histological sections [5, 25]. However, MVD has several substantial limitations mainly owing to the complex biology of tumor microvasculature [26] and the irregular geometry that microvascular systems assume in real space [27]. Until now, the finding that MVD in the normal anterior pituitary was significantly higher than that in tumors was generally accepted $[3,7]$. However, the differences in MVD among adenoma histotypes are highly discordant in the literature. Adenomas with higher MVD are thyrotroph 

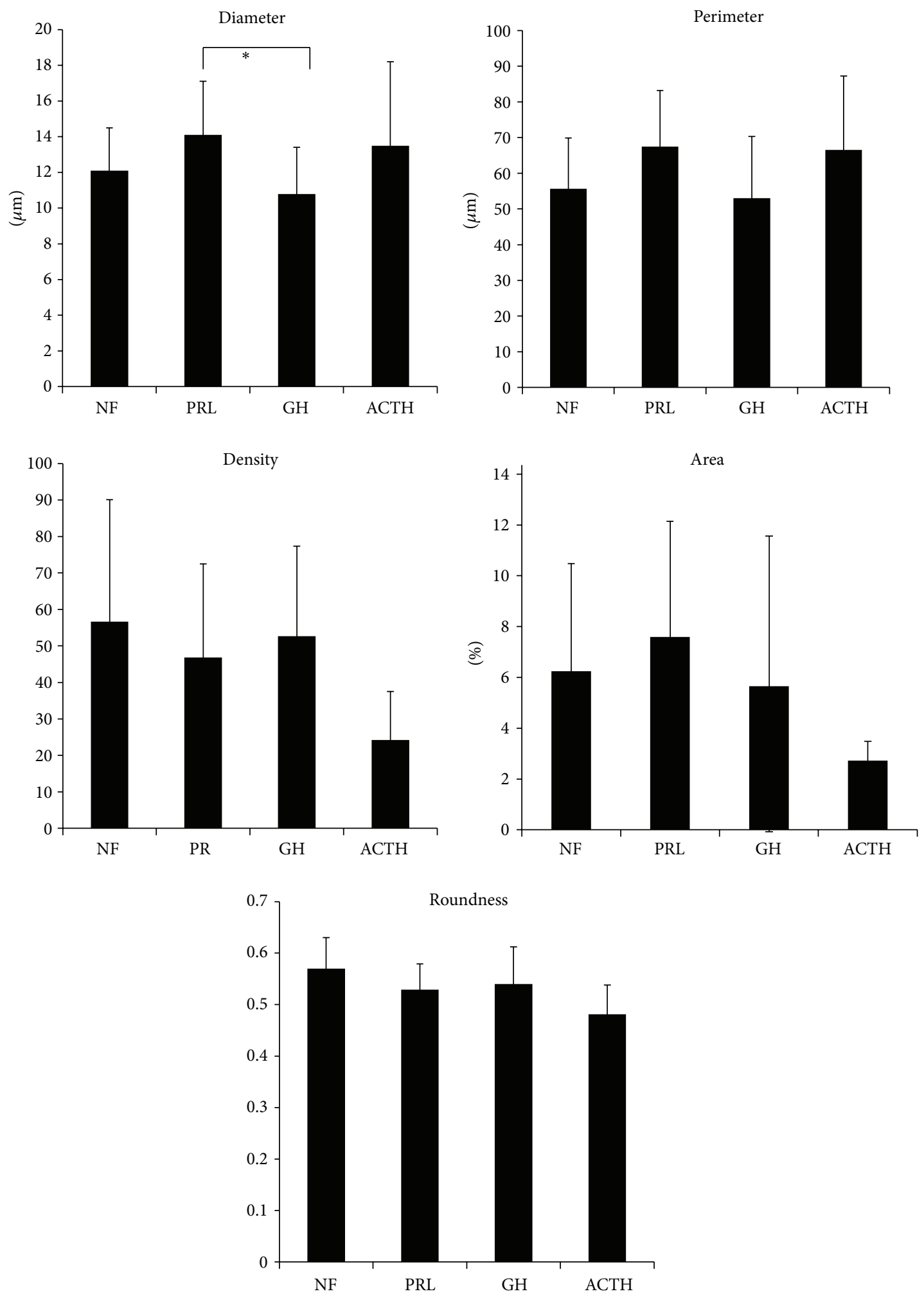

FIGURE 4: Differences in the vascular architecture of all types of pituitary adenomas. Vessel diameter is significantly larger in prolactinsecreting adenomas than GH-secreting adenomas. Vessel density, area, and roundness are lower tendency in ACTH-secreting adenoma than nonfunctioning adenomas. ${ }^{*} P<0.05$. 

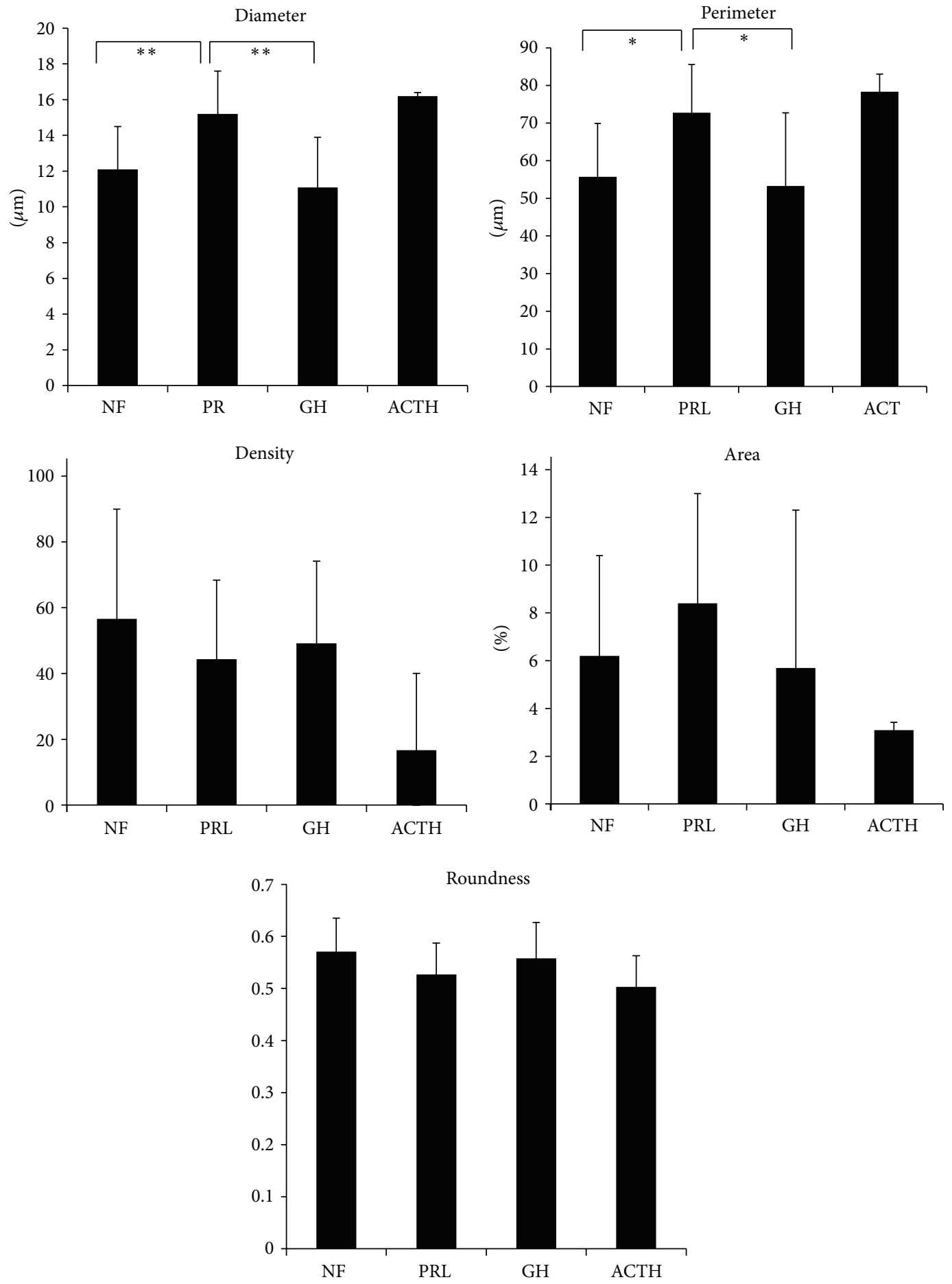

FIGURE 5: Differences of vascular architecture in macroadenoma. Vessel diameter and perimeter are significantly larger in prolactin-secreting adenomas than nonfunctioning and GH-secreting adenomas. ${ }^{*} P<0.05 ;{ }^{* *} P<0.01$.

cell adenomas, while those with lower MVD are PRL cell adenomas [6]. Micro- and macroadenomas that secrete $\mathrm{GH}$ or ACTH have comparable vascular densities, whereas macroprolactinomas are significantly more vascular than microprolactinomas [8].
Several methods for quantitatively analyzing pituitary adenoma microvasculature besides MVD have been applied. Fractal analysis is emerging as a potential effective model for this aim [1]. In addition, the combination of different types of immunostaining techniques such as CD105 (Endoglin) 


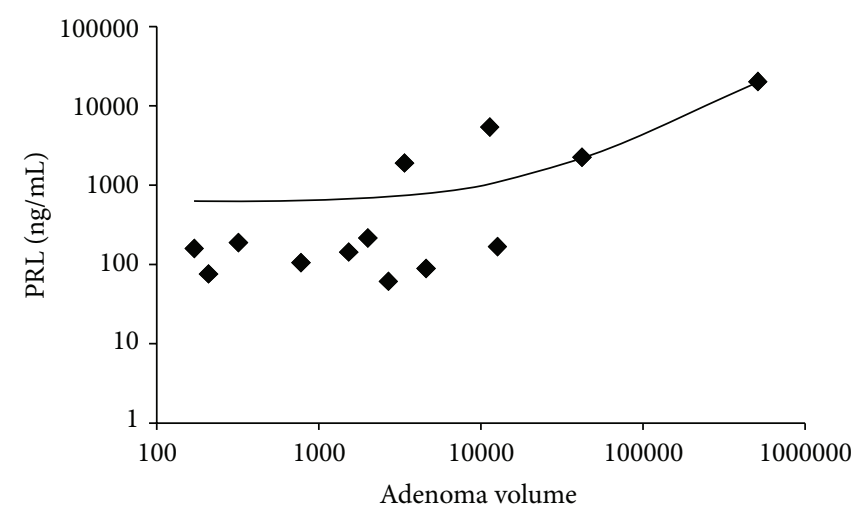

(a)

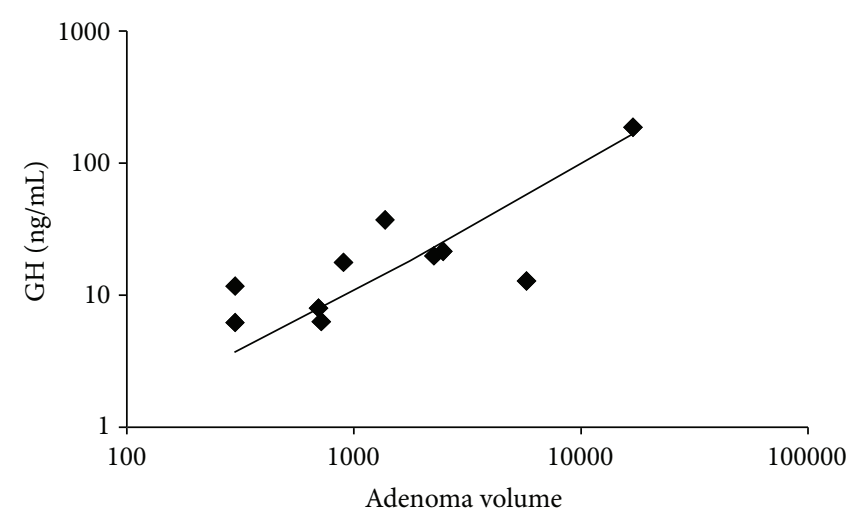

(b)

FIGURE 6: Correlation between adenoma volume and hormone value. (a) Prolactin-secreting adenomas. (b) GH-secreting adenomas.

$[28,29]$ and Endocan [30] for the detection of microvessels in pituitary adenomas by using fractal analysis is an objective computer-aided technique for quantifying and describing the morphological aspects of microvessels that has potential implications in future clinical and surgical applications [2].

Geometrically, human vascularity is a complex threedimensional system; its sizes, shapes, and connecting patterns are highly variable in two-dimensional histological sections. This geometrical complexity is the main cause of discordant results when assessing microvascularity in surgical tissue specimens [1].

In 2003, Vidal et al. suggested using microvascular structural entropy as a new index for the simultaneous measurement of the size of vessels and their arrangements in two-dimensional sections of pituitary tumors [31]. They found that microvascular structural entropy is significantly higher in pituitary adenomas than PRL-secreting carcinomas. In 2007, Di leva et al. first estimated the global complexity of the two-dimensional microvasculature of normal pituitary glands and pituitary adenomas by quantifying their box counting fractal dimension [1]. They found that the microvasculature of normal pituitary specimens is significantly more geometrically complex than that of pituitary adenomas. On the basis of the principles of fractal geometry, this indicates normal pituitary tissue is more vascularized than pituitary adenomas and that the microvasculature of normal pituitary glands is more complex than that of pituitary adenomas. These studies collectively highlight the importance of using geometrical vascular architectural elements other than MVD to evaluate the complex form of tumor vascularity.

However, these geometrical analyses require complex calculations. MVD is only one functional aspect of a tumor microvascular bed; other aspects such as morphology (i.e., tortuosity, branching pattern, and microvessel diameter), maturation, and endothelial wall permeability represent equally important attributes. Among these vessel architecture parameters, we chose simple parameters-vessel diameter, perimeter, and roundness-in addition to MVD. The results demonstrate the importance of vessel diameter and perimeter as biomarkers of different histotypes; PRL-secreting adenomas had larger vessel diameter and perimeter than nonfunctioning and $\mathrm{GH}$-secreting adenomas.

4.3. Significance of Larger Vessel Diameter and Perimeter in PRL-Secreting Adenomas. With regard to PRL-secreting adenomas, vascularity evaluated by MVD is reported to be related to pretreatment hormone production, invasiveness, and surgical cure with lower vascularity [8]. However, whether PRL also influences endothelial cells and whether there are functional consequences of PRL-induced signaling from the perspective of angiogenesis remains elusive. PRL directly stimulates endothelial cell migration and tube formation both in vitro and in vivo in chorioallantoic membrane [32]. In the present study, serum PRL level was strongly correlated with adenoma volume as described previously. However, serum PRL level did not reflect specific vascular architecture parameters. Hyperprolactinemia with PRL-secreting adenomas may have some effect on tumor vasculature.

Blood vessels are emerging as important PRL targets, contributing to PRL's hormonal functions. PRL promotes angiogenesis and is proteolytically cleaved into vasoinhibins, a family of peptides (including $16 \mathrm{kDa}$ PRL) with potent antiangiogenic and blood vessel regression effects $[33,34]$; $16 \mathrm{kDa}$ PRL impairs functional tumor neovascularization by inhibiting vessel maturation and for the first time demonstrated that an endogenous antiangiogenic agent disturbs notch signaling [35]. Recent results suggest tissue enzymes play an important role in the production of this form of PRL in several tissues including the retina, myocardium, and mammary glands. The cleavage leading to the production of $16 \mathrm{kDa}$ PRL may occur extracellularly in the interstitial medium and therefore in the vicinity of blood capillaries [36].

Like PRL-secreting adenomas, circulating levels of PRL are elevated in diabetes; accordingly, they are higher in diabetes patients without retinopathy than in those with proliferative diabetic retinopathy, which is an angiogenic 
disease. Circulating PRL influences the progression of diabetic retinopathy after its intraocular conversion to vasoinhibins. Therefore, inducing hyperprolactinemia may represent a novel treatment strategy against diabetic retinopathy [37].

The synthesis of antiangiogenic factors by tumor cells has been demonstrated. Actively growing primary tumors can secrete antiangiogenic factors into the circulation as is the case for angiostatin and endostatin, which can maintain tumors in a dormant state $[38,39]$. It remains unknown if PRL-secreting adenomas can produce antiangiogenic factors such as $16 \mathrm{kDa}$ PRL. PRL and/or its inhibitor may directly influence adenoma vasculature. In gliomas treated with bevacizumab, an anti-VEGF antibody, tumor vasculature becomes dilated and thin, which suggests normalization, compared to that in nontreated tissue in experimental animals [40] and humans [41, 42]. In contrast, in human corneal neovascularization, topical bevacizumab decreases corneal vessel diameter [43]. Meanwhile, the effect of somatostatin analog treatment on vessel diameter in PRL-secreting adenomas would be interesting to investigate in the future.

4.4. Significance of Vessel Architecture in ACTH-Secreting Adenomas. There are few studies concerning ACTH-secreting adenomas, vascularity, and/or vascular architecture. Among 46 adenomas (18 nonfunctioning, 12 ACTH-secreting, 12 $\mathrm{GH}$-secreting, and $4 \mathrm{PRL}$-secreting), there was no difference among histotypes with respect to MVD [3]. In another report of 112 (30 GH-secreting, 25 PRL-secreting, 15 ACTHsecreting, and 42 nonfunctioning tumors) and 13 normal anterior pituitary gland specimens, ACTH-secreting adenomas were, like microprolactinomas, had much lower vascular density than the normal pituitary tissue and other secreting and nonsecreting tumor types [7]. Micro- and macroadenomas that secrete ACTH have comparable vascular densities [8]. In the present study, ACTH-secreting adenomas tended to have larger vessel diameter and perimeter and lower density than nonfunctioning and GH-secreting adenomas.

The direct action of ACTH on vessels has not been reported. However, the direct actions of cortisol on endothelial cells and vascular permeability have been demonstrated. Interestingly, glucocorticoids directly interact with glucocorticoid receptors on vascular endothelial cells to inhibit tube-like formation. This action is due to alterations in cell morphology rather than the inhibition of endothelial cell viability, migration, or proliferation and may be mediated in part by the induction of thrombospondin-1 [44]. Therefore, ACTH-secreting adenomas may alter vascular architecture.

\section{Conclusion}

VEGF expression plays little role in angiogenesis in pituitary adenomas. Taken together the fact that pituitary adenomas are hypovascular compared to the normal pituitary gland, in biological terms, we can speculate that pituitary adenomas may progress via a nonangiogenic and VEGF-independent pathway. The differences in vessel architecture in different histotypes, particularly larger vessel diameter and perimeter in PRL-secreting adenomas than nonfunctioning and GHsecreting adenomas, suggest the hormonal regulation of vessel architecture other than angiogenesis.

\section{Conflict of Interests}

The authors declare that there is no conflict of interests regarding the publication of this paper.

\section{Acknowledgments}

The authors gratefully acknowledge Yoshiko Tsukada and Makiko Miyagawa for their excellent technical assistance. This work was supported in part by a Grant-in-Aid for Scientific Research from the Ministry of Education, Culture, Sports, Science, and Technology of Japan (no. 24390339 to S. T.), the Japan Brain Foundation (to S. T.), and the Japanese Foundation for Multidisciplinary Treatment of Cancer (to S. T.).

\section{References}

[1] A. Di leva, F. Grizzi, G. Ceva-Grimaldi et al., "Fractal dimension as a quantitator of the microvasculature of normal and adenomatous pituitary tissue," Journal of Anatomy, vol. 211, no. 5, pp. 673-680, 2007.

[2] A. Di Ieva, A. Weckman, J. Di Michele et al., "Microvascular morphometrics of the hypophysis and pituitary tumors: from bench to operating theatre," Microvascular Research, vol. 89, pp. 7-14, 2013.

[3] P. Viacava, M. Gasperi, G. Acerbi et al., "Microvascular density and vascular endothelial growth factor expression in normal pituitary tissue and pituitary adenomas," Journal of Endocrinological Investigation, vol. 26, no. 1, pp. 23-28, 2003.

[4] C. Cristina, M. I. Perez-Millan, G. Luque et al., "VEGF and CD31 association in pituitary adenomas," Endocrine Pathology, vol. 21, no. 3, pp. 154-160, 2010.

[5] E. Jasek, A. Furgal-Borzych, G. J. Lis, J. A. Litwin, E. RzepeckaWozniak, and F. Trela, "Microvessel density and area in pituitary microadenomas," Endocrine Pathology, vol. 20, no. 4, pp. 221226, 2009.

[6] M. Niveiro, F. I. Aranda, G. Peiró, C. Alenda, and A. Picó, "Immunohistochemical analysis of tumor angiogenic factors in human pituitary adenomas," Human Pathology, vol. 36, no. 10, pp. 1090-1095, 2005.

[7] H. E. Turner, Z. Nagy, K. C. Gatter, M. M. Esiri, A. L. Harris, and J. A. H. Wass, "Angiogenesis in pituitary adenomas and the normal pituitary gland," The Journal of Clinical Endocrinology \& Metabolism, vol. 85, no. 3, pp. 1159-1162, 2000.

[8] H. E. Turner, Z. Nagy, K. C. Gatter, M. M. Esiri, A. L. Harris, and J. A. H. Wass, "Angiogenesis in pituitary adenomasrelationship to endocrine function, treatment and outcome," $v$, vol. 165, no. 2, pp. 475-481, 2000.

[9] N. S. Vasudev and A. R. Reynolds, "Anti-angiogenic therapy for cancer: current progress, unresolved questions and future directions," Angiogenesis, vol. 17, no. 3, pp. 471-494, 2014.

[10] A. Sav, F. Rotondo, L. V. Syro, B. W. Scheithauer, and K. Kovacs, "Biomarkers of pituitary neoplasms," Anticancer Research, vol. 32, no. 11, pp. 4639-4654, 2012. 
[11] N. Ferrara and W. J. Henzel, "Pituitary follicular cells secrete a novel heparin-binding growth factor specific for vascular endothelial cells," Biochemical and Biophysical Research Communications, vol. 161, no. 2, pp. 851-858, 1989.

[12] N. Ferrara and W. J. Henzel, "Pituitary follicular cells secrete a novel heparin-binding growth factor specific for vascular endothelial cells. 1989," Biochemical and Biophysical Research Communications, vol. 425, no. 3, pp. 540-547, 2012.

[13] C. Clapp, S. Thebault, M. C. Jeziorski, and G. Martínez De La Escalera, "Peptide hormone regulation of angiogenesis," Physiological Reviews, vol. 89, no. 4, pp. 1177-1215, 2009.

[14] N. M. Neary, O. J. Booker, B. S. Abel et al., "Hypercortisolism is associated with increased coronary arterial atherosclerosis: analysis of noninvasive coronary angiography using multidetector computerized tomography," The Journal of Clinical Endocrinology \& Metabolism, vol. 98, no. 5, pp. 2045-2052, 2013.

[15] M. Thomas, M. Keramidas, E. Monchaux, and J.-J. Feige, "Role of adrenocorticotropic hormone in the development and maintenance of the adrenal cortical vasculature," Microscopy Research and Technique, vol. 61, no. 3, pp. 247-251, 2003.

[16] S. Takano, Y. Kato, T. Yamamoto et al., "Immunohistochemical detection of IDH1 mutation, p53, and internexin as prognostic factors of glial tumors," Journal of Neuro-Oncology, vol. 108, no. 3, pp. 361-373, 2012.

[17] H. Kamiyama, S. Takano, E. Ishikawa, K. Tsuboi, and A. Matsumura, "Anti-angiogenic and immunomodulatory effect of the herbal medicine "Juzen-taiho-to" on malignant glioma," Biological and Pharmaceutical Bulletin, vol. 28, no. 11, pp. 21112116, 2005.

[18] T. Kitamura, N. Asai, A. Enomoto et al., "Regulation of VEGFmediated angiogenesis by the Akt/PKB substrate Girdin," Nature Cell Biology, vol. 10, no. 3, pp. 329-337, 2008.

[19] S. Takano, K. Tsuboi, A. Matsumura, Y. Tomono, Y. Mitsui, and T. Nose, "Expression of the angiogenic factor thymidine phosphorylase in human astrocytic tumors," Journal of Cancer Research and Clinical Oncology, vol. 126, no. 3, pp. 145-152, 2000.

[20] A. Di Ieva, F. Grizzi, G. Ceva-Grimaldi et al., "The microvascular network of the pituitary gland: a model for the application of fractal geometry to the analysis of angioarchitecture and angiogenesis of brain tumors," Journal of Neurosurgical Sciences, vol. 54, no. 2, pp. 49-54, 2010.

[21] P. Lohrer, J. Gloddek, U. Hopfner et al., "Vascular endothelial growth factor production and regulation in rodent and human pituitary tumor cells in vitro," Neuroendocrinology, vol. 74, no. 2, pp. 95-105, 2001.

[22] K. Kim, D. Yoshida, and A. Teramoto, "Expression of hypoxiainducible factor $1 \alpha$ and vascular endothelial growth factor in pituitary adenomas," Endocrine Pathology, vol. 16, no. 2, pp. 115121, 2005.

[23] R. Sánchez-Ortiga, L. Sánchez-Tejada, O. Moreno-Perez, P. Riesgo, M. Niveiro, and A. M. Picó Alfonso, "Over-expression of vascular endothelial growth factor in pituitary adenomas is associated with extrasellar growth and recurrence," Pituitary, vol. 16, no. 3, pp. 370-377, 2013.

[24] R. Nomura, D. Yoshida, and A. Teramoto, "Stromal cellderived factor-1 expression in pituitary adenoma tissues and upregulation in hypoxia," Journal of Neuro-Oncology, vol. 94, no. 2, pp. 173-181, 2009.

[25] S. Sharma, M. C. Sharma, and C. Sarkar, "Morphology of angiogenesis in human cancer: a conceptual overview, histoprognostic perspective and significance of neoangiogenesis," Histopathology, vol. 46, no. 5, pp. 481-489, 2005.
[26] L. Hlatky, P. Hahnfeldt, and J. Folkman, "Clinical application of antiangiogenic therapy: microvessel density, what it does and doen't tell us," Journal of the National Cancer Institute, vol. 94, no. 12, pp. 883-893, 2002.

[27] F. Grizzi, P. Colombo, B. Barbieri, B. Franceschini, M. Roncalli, and M. Chiriva-Internati, "Microscopic analysis and significance of vascular architectural complexity in renal cell carcinoma," Clinical Cancer Research, vol. 7, no. 10, pp. 3305-3307, 2001.

[28] C. B. Pizarro, M. C. Oliveira, J. F. Pereira-Lima et al., "Evaluation of angiogenesis in 77 pituitary adenomas using endoglin as a marker," Neuropathology, vol. 29, no. 1, pp. 40-44, 2009.

[29] F. Rotondo, S. Sharma, B. W. Scheithauer et al., "Endoglin and CD-34 immunoreactivity in the assessment of microvessel density in normal pituitary and adenoma subtypes," Neoplasma, vol. 57, no. 6, pp. 590-593, 2010.

[30] F. Matano, D. Yoshida, Y. Ishii, S. Tahara, A. Teramoto, and A. Morita, "Endocan, a new invasion and angiogenesis marker of pituitary adenomas," Journal of Neuro-Oncology, vol. 117, no. 3, pp. 485-491, 2014.

[31] S. Vidal, E. Horvath, K. Kovacs, R. V. Lloyd, and B. W. Scheithauer, "Microvascular structural entropy: a novel approach to assess angiogenesis in pituitary tumors," Endocrine Pathology, vol. 14, no. 3, pp. 239-247, 2003.

[32] A. Q. Reuwer, P. Nowak-Sliwinska, L. A. Mans et al., "Functional consequences of prolactin signalling in endothelial cells: a potential link with angiogenesis in pathophysiology?" Journal of Cellular and Molecular Medicine, vol. 16, no. 9, pp. 2035-2048, 2012.

[33] C. Clapp, L. Martínez de la Escalera, and G. Martínez de la Escalera, "Prolactin and blood vessels: a comparative endocrinology perspective," General and Comparative Endocrinology, vol. 176, no. 3, pp. 336-340, 2012.

[34] A. M. Corbacho, G. Martínez de la Escalera, and C. Clapp, "Roles of prolactin and related members of the prolactin/growth hormone/placental lactogen family in angiogenesis," Journal of Endocrinology, vol. 173, no. 2, pp. 219-238, 2002.

[35] N.-Q. Nguyen, K. Castermans, S. Berndt et al., "The antiangiogenic $16 \mathrm{~K}$ prolactin impairs functional tumor neovascularization by inhibiting vessel maturation," PLoS ONE, vol. 6, no. 11, Article ID e27318, 2011.

[36] M. Lkhider, T. Seddiki, and M. Ollivier-Bousquet, "Prolactin and its cleaved $16 \mathrm{kDa}$ fragment," Medecine/Sciences, vol. 26, no. 12, pp. 1049-1054, 2010.

[37] E. Arnold, J. C. Rivera, S. Thebault et al., "High levels of serum prolactin protect against diabetic retinopathy by increasing ocular vasoinhibins," Diabetes, vol. 59, no. 12, pp. 3192-3197, 2010.

[38] Y. Cao, "Endogenous angiogenesis inhibitors: angiostatin, endostatin, and other proteolytic fragments," Progress in Molecular and Subcellular Biology, vol. 20, pp. 161-176, 1998.

[39] M. S. O'Reilly, T. Boehm, Y. Shing et al., "Endostatin: an endogenous inhibitor of angiogenesis and tumor growth," Cell, vol. 88, no. 2, pp. 277-285, 1997.

[40] G. Parmaksiz, M. Czabanka, M. Vinci, and P. Vajkoczy, "Antiangiogenic therapy inhibits the recruitment of vascular accessory cells to the perivascular niche in glioma angiogenesis," Journal of Vascular Research, vol. 51, no. 2, pp. 102-109, 2014.

[41] I. Fischer, C. H. Cunliffe, R. J. Bollo et al., "High-grade glioma before and after treatment with radiation and Avastin: initial observations," Neuro-Oncology, vol. 10, no. 5, pp. 700-708, 2008. 
[42] J. F. de Groot, G. Fuller, A. J. Kumar et al., “Tumor invasion after treatment of glioblastoma with bevacizumab: radiographic and pathologic correlation in humans and mice," Neuro-Oncology, vol. 12, no. 3, pp. 233-242, 2010.

[43] S.-F. Cheng, M. H. Dastjerdi, G. Ferrari et al., "Short-term topical bevacizumab in the treatment of stable corneal neovascularization," American Journal of Ophthalmology, vol. 154, no. 6, pp. 940-948, 2012.

[44] J. J. Logie, S. Ali, K. M. Marshall, M. M. S. Heck, B. R. Walker, and P. W. F. Hadoke, "Glucocorticoid-mediated inhibition of angiogenic changes in human endothelial cells is not caused by reductions in cell proliferation or migration," PLOS ONE, vol. 5, no. 12, Article ID e14476, 2010. 


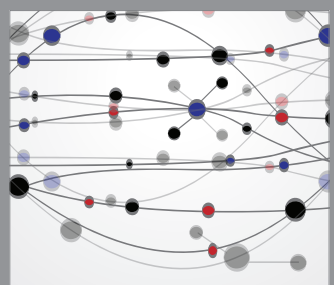

The Scientific World Journal
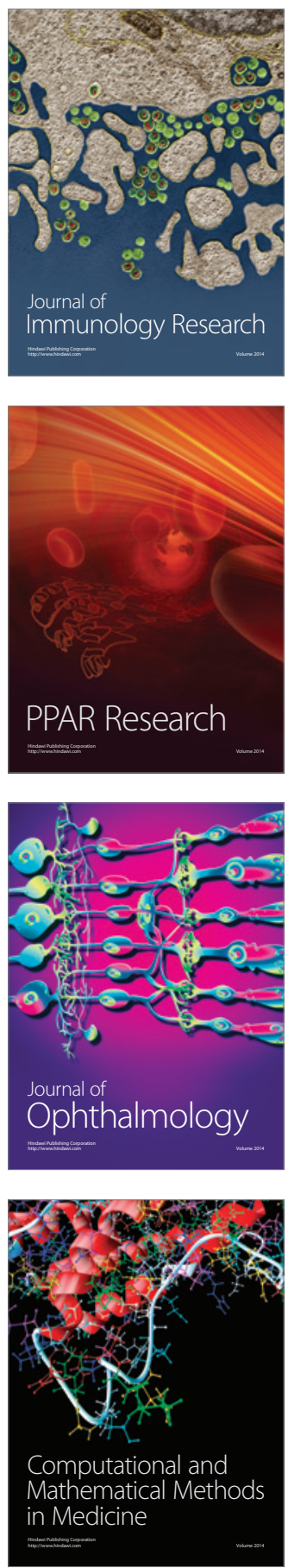

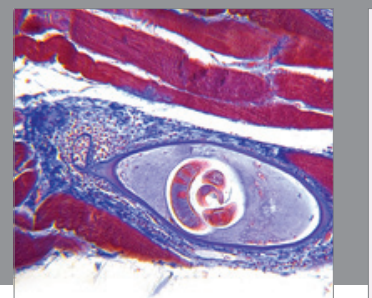

Gastroenterology

Research and Practice
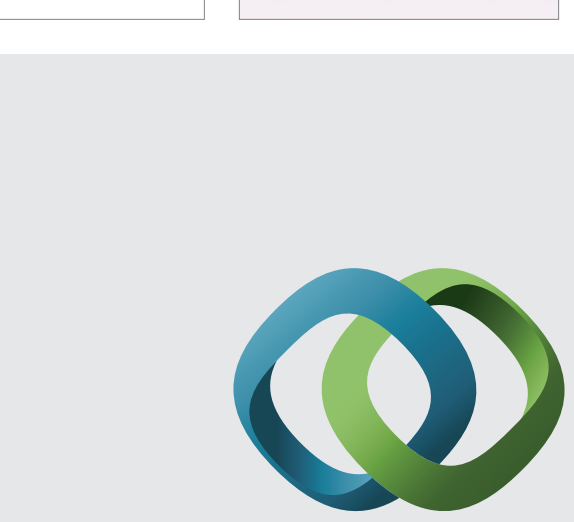

\section{Hindawi}

Submit your manuscripts at

http://www.hindawi.com
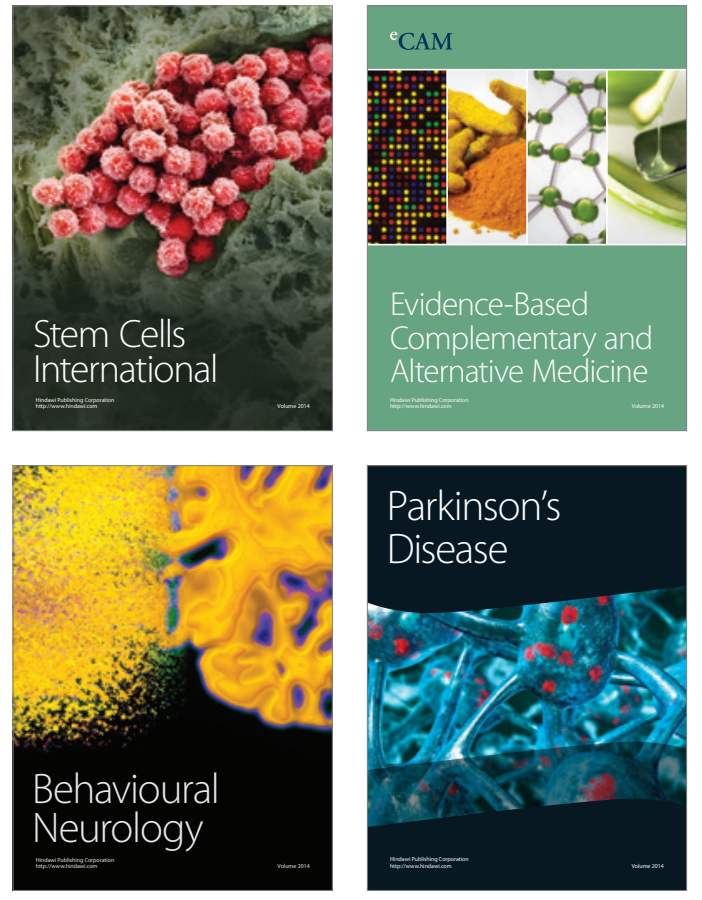
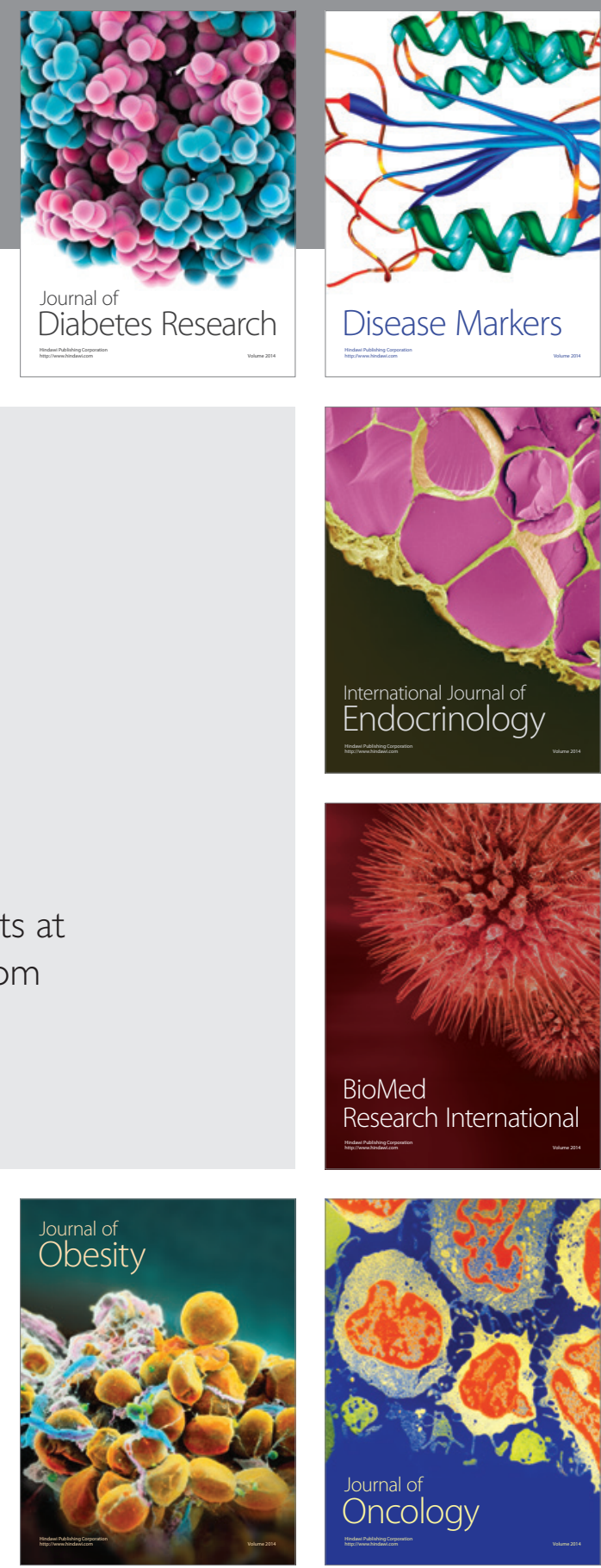

Disease Markers
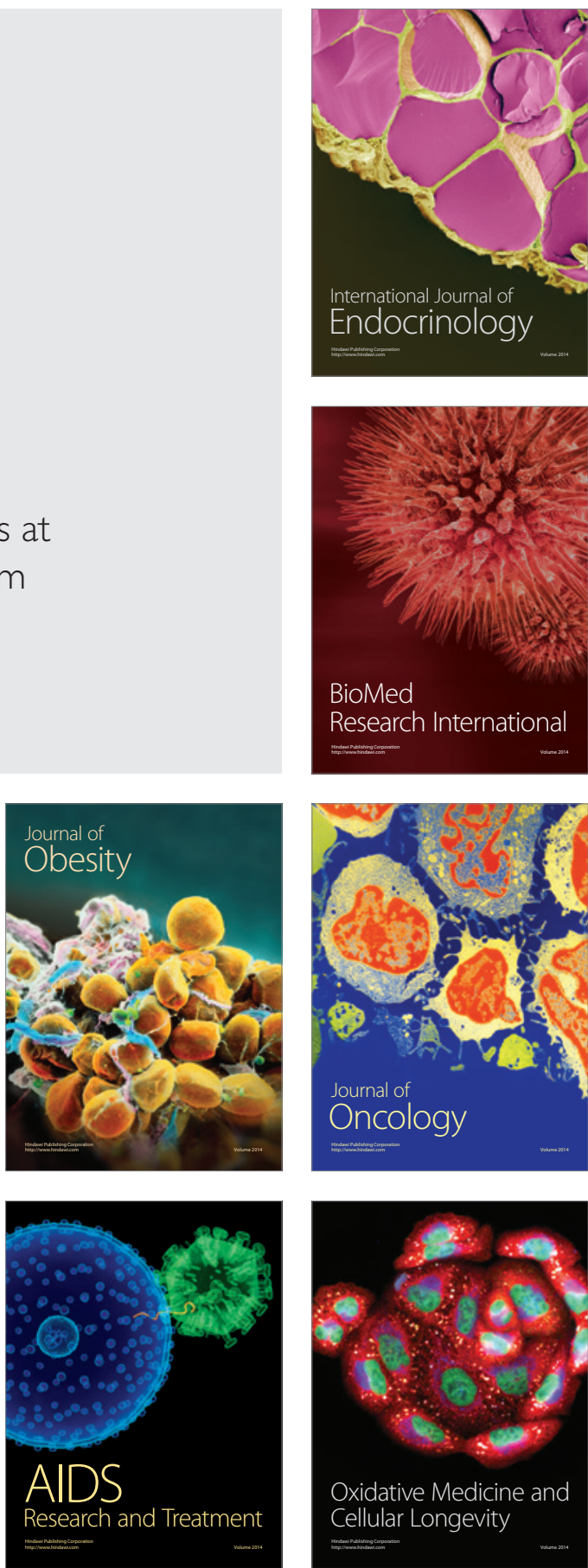